\title{
Analysis of High-Power Diode Laser Heating Effects on HY-80 Steel for Laser Assisted Friction Stir Welding Applications
}

\author{
Maxwell Wiechec ${ }^{1}$, Brad Baker ${ }^{*}$, Terry McNelley², Manyalibo Matthews ${ }^{3}$, \\ Alexander Rubenchik ${ }^{3}$, Mark Rotter ${ }^{3}$, Ray Beach ${ }^{3}$, Sheldon $\mathrm{Wu}^{3}$ \\ ${ }^{1}$ United States Naval Academy, Annapolis, MD, USA \\ ${ }^{2}$ Naval Postgraduate School, Monterey, CA, USA \\ ${ }^{3}$ Lawrence Livermore National Laboratory, Livermore, CA, USA \\ Email: maxwiechec@gmail.com, *bbaker@usna.edu,tmcnelley@nps.edu, matthews11@1lnl.gov, rubenchik1@1ln1.gov, \\ rotter1@llnl.gov, beach2@1lnl.gov,wu31@1lnl.gov
}

How to cite this paper: Wiechec, M., Baker, B., McNelley, T., Matthews, M., Rubenchik, A., Rotter, M., Beach, R. and Wu, S. (2017) Analysis of High-Power Diode Laser Heating Effects on HY-80 Steel for Laser Assisted Friction Stir Welding Applications. World Journal of Engineering and Technology, 5, 97-112.

https://doi.org/10.4236/wjet.2017.51009

Received: December 2, 2016

Accepted: February 25, 2017

Published: February 28, 2017

Copyright $\odot 2017$ by authors and Scientific Research Publishing Inc. This work is licensed under the Creative Commons Attribution International License (CC BY 4.0).

http://creativecommons.org/licenses/by/4.0/

(c) (i) Open Access

\begin{abstract}
In this research, several conditions of high power diode laser heated HY-80 steel were characterized to determine the viability of using such lasers as a preheating source before friction stir welding in order to reduce frictional forces thereby reducing tool wear and increasing welding speeds. Differences in microstructures within heat affected zones were identified at specific laser powers and traverse speeds. Vickers hardness values were recorded and analyzed to validate the formation of additional martensite in diode laser heated regions of HY-80 steel. Conditions that produced little to no additional martensite were identified and relationships among high power diode laser power, traverse speed, and martensite formation were determined. The development of heat affected zones, change in grain structure, and creation of additional martensite in HY-80 can be prevented through the optimization of laser amperage and transverse speed.
\end{abstract}

\section{Keywords}

Mechanical Characterization, Martensite, Welding, Martensitic

Transformations

\section{Introduction}

Friction stir welding (FSW) is a modern solid-state joining technique that is energy efficient, environmentally friendly, and versatile which has been in use for over two decades on both soft alloys such as aluminum and harder alloys 
such as steels [1] [2] [3]. Some of the advantages of FSW over conventional joining techniques include usage of no filler material, expenditure of no shielding gas to the environment, and consumption of considerably less energy than conventional welding methods. The superiority of FSW welds is evident in the low distortion of the workpiece, good dimensional stability, no loss of alloying elements, excellent material properties in the joint area, refinement of microstructure, and absence of solidification and hot cracking, all of which arise from the fact that FSW is a solid-state joining process [3]. Despite these positive attributes, FSW does have some disadvantages related to the nature of frictional heating and the forces between tool and the workpiece which have limited its use across a wider range of industrially-relevant materials.

Wear of tools used during FSW is a critical issue and is discussed in detail by several authors [3] [4] [5] [6]. For softer metals such as aluminum, frictional forces between the tool and workpiece are relatively low, leading to less tool wear and thereby allowing the use of simpler tool designs that can have a long useful lifetime. FSW on harder materials such as steel alloys results in significantly larger frictional forces causing reduced tool life and requiring stronger, more expensive tools to compensate. The combination of increased tool cost, tool wear, and reduced welding speeds is one of the primary industrial limitations of FSW on steels.

As an alternative to hardening tool material to minimize tool wear, softening of the base metal prior to FSW is a viable solution to increase tool life, and several hybrid FSW methods involving workpiece preheating have been proposed [7]-[13]. Many of the original hybrid FSW techniques used traditional fusion welding heat input mechanisms, but more recently laser-based hybrid FSW concepts have been proposed that offer simple, effective, and controllable means of preheating [14] [15] [16] [17]. Frictional forces are directly related to the downward force of the tool as well as the shear force once the tool is rotating [3] [18] [19]. Softening of high strength materials below their recrystallization temperature moments before being friction stir welded should reduce tool wear while also causing minimal change to the workpiece. As an example, Ferrando confirmed that electronically-assisted friction stir welding (EAFSW) does reduce the downward force required for proper metal joining [7]. Unfortunately, since EAFSW requires additional contact with the workpiece and relies on energy transfer through the workpiece to the weld area, it is highly application and material dependent and therefore may not be viable for a broad range of applications. Similarly, Kohn demonstrated that a fiber-coupled Nd:YAG laser could be used to locally preheat the workpiece without physical contact, showing the potential behind laser assisted friction stir welding (LAFSW) in reducing tool wear and increasing welding speeds [14].

Unlike the large and generally complex Nd:YAG or $\mathrm{CO}_{2}$ lasers and the comparatively more expensive $\mathrm{Yb}$ fiber lasers proposed in current LAFSW systems, high-power diode lasers (HPDL) are compact, less expensive, more efficient, safer and comparatively easier to operate. The advantages and potential applica- 
tions of HPDL systems are discussed in detail in reviews by Li [20], Chen [21], and Bachmann [22]. Additionally, HPDLs can have adjustable wavelengths allowing for increased absorption and efficiency further adding to their flexibility [17]. Assisting FSW with the use of HPDL systems was initially proposed as Diode Laser Assisted Friction Stir Welding (DLAFSW), where the flexibility of HPDL systems was a key consideration for controlling preheating and post FSW cooling on hardenable steels [17]. This research aims to add to that proposal by characterizing the microstructural changes due to laser heating with HPDLs alone.

In order to demonstrate the effect of laser heating on typical hardenable steels, the tempered martensitic steel HY-80 was selected as a candidate workpiece. HY-80 steel is a high-strength low-carbon steel best known for its use in ship construction and military applications. Having a high tensile and yield strength, HY-80 is used extensively for hulls of Naval vessels and submarines. The Naval lineage of HY-80 is discussed in detail by Heller [23], Stewart [24], and Young [25]. HY-80 is primarily used in a quenched and tempered condition that results in a tempered martensitic microstructure which produces the desirable strength and hardness.

When used on HY-80, a HPDL will be able to provide a highly controllable heating source required for FSW of hardenable steels. With control over the laser parameters, the temperature at the heating location can be regulated, controlling the phase transformation that traditionally complicates the welding process of hardenable steels. With the location and precise amount of heat under control, it is anticipated that heating will be in a confined area, thus preserving the mechanical properties of the base metal. Additionally, the precision of HPDL systems may allow for heating below phase transition temperatures.

Although not desirable for pre-weld treatment in DLAFSW, the use of HPDL systems on hardenable steels offers a separate possibility of surface hardening. As opposed to softening prior to FSW, a HPDL can be used to locally raise the surface temperature of a workpiece to promote the formation of martensite without applying energy throughout the material. Because of its low cost, a HPDL is a cost effective means for large area processing and therefore could be used to harden a large area. Shi et al. found that lasers are ideal tools for surface hardening below the melting temperature of steel, producing a hardened depth of around $1 \mathrm{~mm}$ using a $600 \mathrm{~W}$ laser with a beam diameter of $5 \mathrm{~mm}$ [26]. Thus, aside from preheating to soften the workpiece, surface hardening with HPDL arrays can be considered for future research as there are many applications for localized and efficient hardening; however, such applications will not be discussed in detail in this research.

If controllable heating using HPDLs proves successful, DLAFSW could be used to provide higher quality welds with a smaller heat affected zone (HAZ) producing more desirable material joints. Additionally, conventional FSW is already used extensively on aluminum alloys for newer Naval ships, and DLAFSW could have great potential in improving these joints as well [27]. Finally, since 
future nuclear reactor designs use high strength superalloys which cannot be joined by typical joining methods, FSW has been proposed as a joining method for these alloys in nuclear applications.

This research analyzes HPDL heated HY-80 samples for the optimum laser settings before FSW. Ideally, no additional martensite will have formed, grain size through the heated region will be consistent with the base material, and hardness will be uniform. If HY-80 is heated past its transition temperature, additional martensite will form, creating a HAZ with undesirable brittleness, stiffness, and low toughness. As a result of this research, the laser heating effects of HPDLs on HY-80 for DLAFSW applications, and the possibility of laser hardening, will be explored using microstructure and material characterization based on high resolution microscopy and hardness measurements.

\section{Experimental Procedure}

HY-80 was selected for this study based on previous FSW experience and its similarity to other hardenable steels. In this study we used rolled plates of HY-80 (MIL-S-16216) which were $6.4 \mathrm{~mm}$ (0.25 inches) thick and of varying widths and lengths. As discussed previously, HY-80 is a low carbon steel (0.12 - 0.18 wt\% carbon) used in Naval applications as well as some pressure vessels and acquires its strength and toughness through quenching and tempering treatments. Table 1 gives the composition limits for HY-80 steel according to MIL-S-16216 as well as the composition of the HY-80 used in this research as determined by energy dispersive spectroscopy (EDS). For the EDS results presented in this research, the compositional values for carbon were not included due to the inaccuracies associated with the low energy characteristic X-rays of carbon. Additionally, impurities such as sulfur and phosphorous were not included since their composition were well below $0.1 \mathrm{wt} \%$ and within specification.

Previous research on FSW of HY-80 has shown that peak temperatures in the stir zone are sufficient to create austenite which upon cooling will become tempered or untempered martensite based on the cooling rates [28]. Depending on the intended application, the formation of martensite in the weld nugget can be beneficial or detrimental, but in most applications requiring toughness, the formation of an untempered martensite phase is undesirable so consideration must

Table 1. Chemical composition for HY-80 (in wt\%).

\begin{tabular}{cccc}
\hline Element & $\begin{array}{c}\text { HY-80 nominal } \\
\text { composition }\end{array}$ & Base Material & Heat Affected Zone \\
\hline $\mathrm{C}$ & $0.12-0.18$ & - & - \\
$\mathrm{Si}$ & $0.15-0.35$ & 0.18 & 0.18 \\
$\mathrm{Mo}$ & $0.20-0.60$ & 0.31 & 0.21 \\
$\mathrm{Cr}$ & $1.00-1.8$ & 1.24 & 1.38 \\
$\mathrm{Ni}$ & $2.00-3.25$ & 1.91 & 1.69 \\
$\mathrm{Cu}$ & 0.25 max & 0.29 & 0.19 \\
$\mathrm{Fe}$ & balance & 95.0 & 95.4 \\
\hline
\end{tabular}


be given to cooling rates following joining in order to establish a tempered martensitic microstructure. Although considered and established as a future research goal, no specific post welding heat treatment was applied in this research.

Several plates of HY-80 were laser heated in accordance to the procedure discussed in related research [17]. The HPDL used was a $5 \mathrm{~kW}$ Northrup Grumman diode array that emits partially-coherent light at a wavelength of $795 \mathrm{~nm}$. Over a drive current range of 20 to $50 \mathrm{amps}$, the array generates optical powers between 160 and $2100 \mathrm{~W}$, thus allowing for wide range of temperatures on the workpiece. Figure 1 shows a series of experimental runs to measure of beam profile and establish the operating conditions of the HPDL array [17].

Figure 1 shows that increasing the laser current causes a change in the beam profile (Figure 1(A)) as well as a linear increase in power above a lasing threshold of $\sim 17$ amps (Figure $1(B)$ ). Increasing the beam current causes a proportionally larger expansion of the beam in the axis corresponding to the direction perpendicular to the laser and proposed welding path ("slow" axis of the laser diode emission) and relates closely to the width of laser scarring found on the heated plates (Figure 2). Increasing the beam current clearly causes an increase in the width of the visibly heated area as suggested by the beam dump analysis shown in Figure 1(A).

Parameters for testing were chosen based on predicted optimum FSW conditions on HY-80 by Young et al:: 400 revolutions per minute (RPM) for rotational

(A)
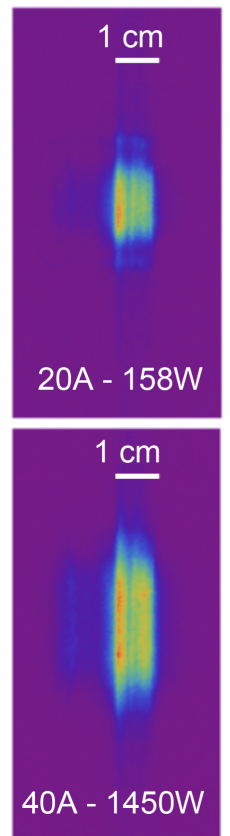
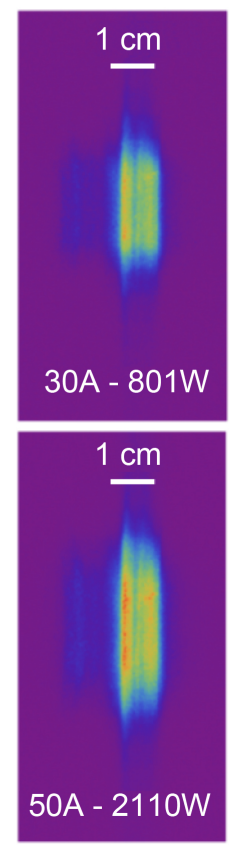

(B)

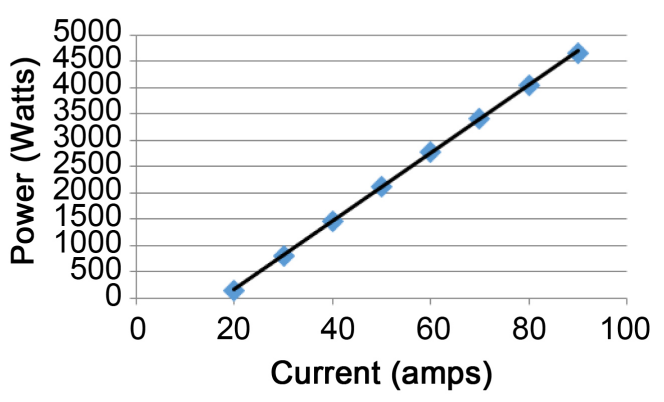

Y

(slow axis)

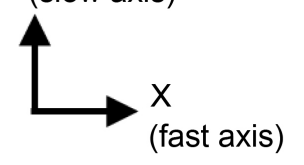

Direction of beam path

Figure 1. (A) High power diode laser (HPDL) beam profile at varying currents (measured on a beam dump not the HY-80 workpiece) and (B) power versus current of the HPDL array. Slow axis and fast axis refer to divergence of the laser diode array. The fast axis is the axis perpendicular to the plane of the diode waveguide and corresponds to steeper divergence. 


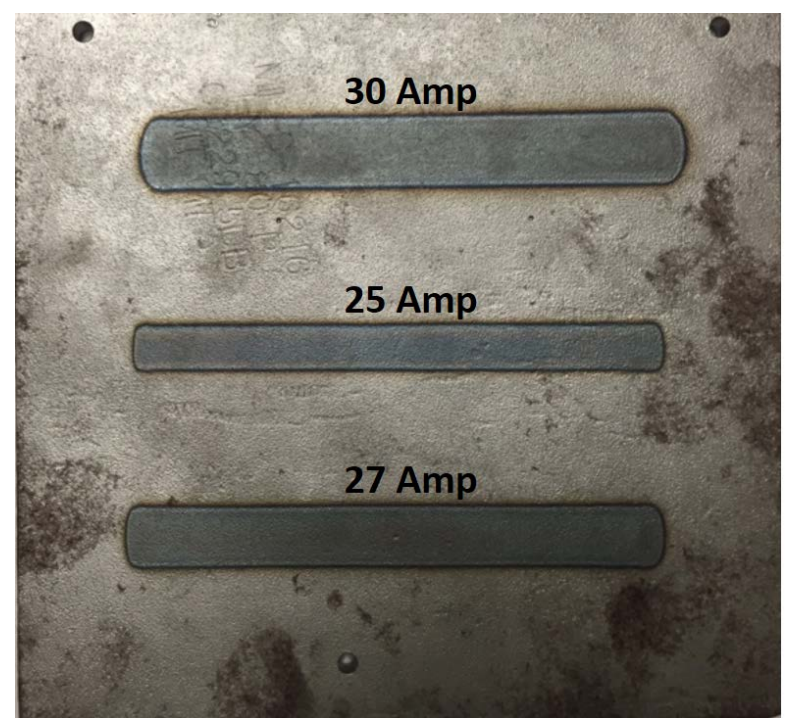

Figure 2. Top view of example HY-80 plate with three different laser preheating runs showing the size and shape of the heated area with respect to laser amperage. The size and shape of the heated area is similar to the path of a typical friction stir welding tool.

speed and 100 millimeters per minute (MMPM) for traverse or scan speed [25]. Since this research focuses solely on laser effects on HY-80, only the traverse speed recommended by Young is relevant. The rotational speed will become important when the two components of FSW and HPDL heating are combined in DLAFSW research. Based on initial laser heating trials and estimates reported in related research, the optimal current conditions were determined to be between 25 amps and 30 amps [17]. Additionally, all runs were performed on bead-blasted surfaces to eliminate variability in absorptivity across runs. Workpiece surface preparation does have a significant impact on laser absorptivity and a resultant impact on heating. Analysis of different surface preparations will be reported in a separate report. The major conditions analyzed in this research are summarized in Table 2.

In addition to the conditions listed in Table 2, optimum conditions may include varying the current of the laser shortly after movement begins. Preheating without movement at a current below 25 amps may be considered for additional workpiece heating without passing the austenitic transition temperature. Experiments based on these variable heating conditions were performed and an image of the laser heated plate can be found in Figure 3; however, no characterization was performed on this specific plate in this research since an analysis of steady state heating conditions was desirable. Nonetheless, these results demonstrate the effect of near instantaneous $(<1 \mathrm{~ms})$ laser heating changes on surface treatment and the associated responsiveness. Figure 3 also shows the nominal surface temperature of the heated plate using thermally sensitive lacquers applied across the heated path.

For this research, two plates with three runs each were the primary focus with 
Table 2. Summary of laser heating conditions analyzed consisting of three current conditions and three different traverse speeds.

\begin{tabular}{cccc}
\hline $\begin{array}{c}\text { Current } \\
\text { (Amps) }\end{array}$ & Power (W) & Nominal Heat Input & Traverse Speed (MMPM) \\
\hline 30 & 800 & High heat input & 200 \\
30 & 800 & High heat input & 150 \\
30 & 800 & High heat input & 100 \\
27 & 612 & Moderate heat input & 100 \\
25 & 158 & Low heat input & 100 \\
\hline
\end{tabular}

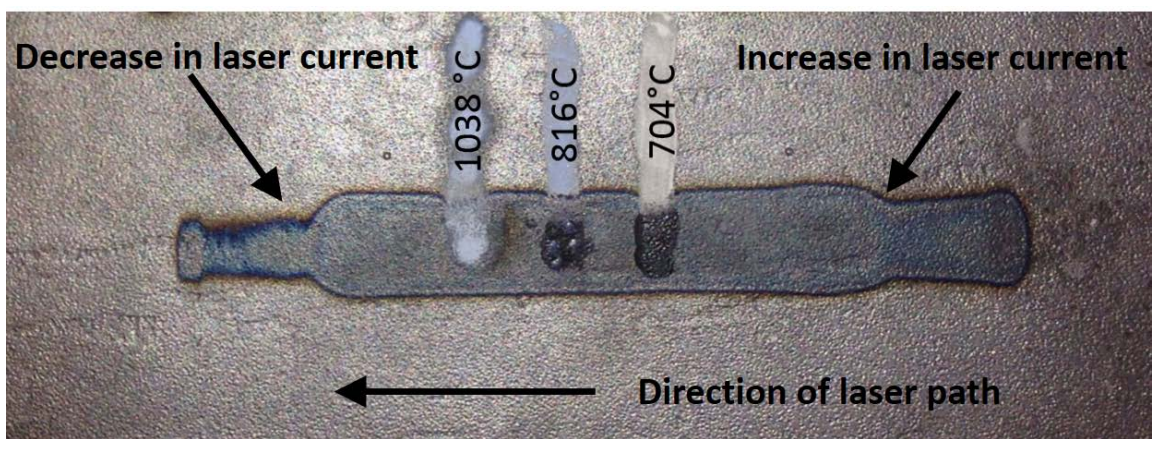

Figure 3. Proposed condition with increasing laser current to $30 \mathrm{amps}$ followed by reduction in current to 25 amps at the end of the laser run. Temperature sensitive lacquers with transition temperature shown were applied prior to heating to indicate nominal surface temperature.

important conditions summarized in Table 2. Specimens were cut, polished, and mounted in conductive resin for subsequent analysis. All samples used in this research were mounted such that the transverse side would be visible from the mount for inspection of the laser effects below the surface of the metal. Specimens were not subjected to any additional heating during sample preparation.

Samples were prepared with $\mathrm{SiC}$ papers and diamond polishing solutions. Samples for microscopy were etched with $2 \% \mathrm{Nital}$ and were analyzed in an optical microscope and a field emission gun scanning electron microscope (SEM) at $15 \mathrm{keV}$. EDS was also performed on the base material and the HAZ to determine if any change in composition of an element in any particular area.

After imaging, the hardness of transverse specimens was measured using a micro-indenter on a Vickers scale. Indentations were made with a 500 gram load and 15 second dwell time. Hardness measurements were taken with a separation distance of 3 - 5 times the indentation width to prevent interference due to strain hardening from nearby indentations. Hardness measurements were recorded in representative areas of the base metal and heat affected zones for each test specimen.

\section{Results}

\subsection{Base Metal}

The microstructure in the base material is tempered martensite as shown in 
Figure 4. The grains are comparatively larger than the grains in the HAZ following laser heating and their shape resembles that of prior austenitic grains that transformed into tempered martensite during the original production processing of HY-80. Similar grain structures were observed using a SEM, as seen in Figure 4(b). Results for the base material from all conditions were consistent and images were similar. The hardness of the base material was experimentally determined to be 240 HV0.5 throughout all samples.

\subsection{Heat Affected Zone}

\subsubsection{High Heat Input ( $30 \mathrm{amp}, 807 \mathrm{~W}$ )}

The microstructure in the HAZ for the $30 \mathrm{amp}$ condition is coarse tempered martensite as shown in Figure 5. The grains are smaller than those found in the

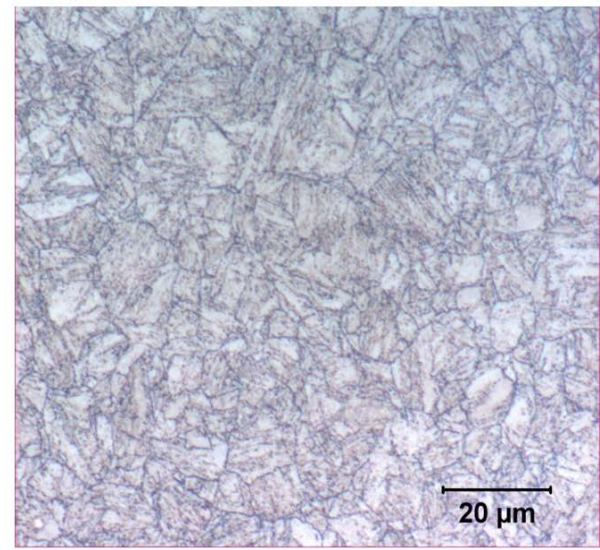

(a)

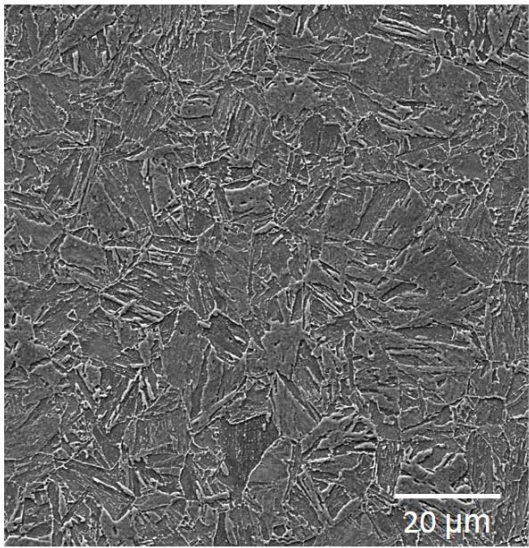

(b)

Figure 4. (a) Optical micrograph and (b) scanning electron microscope secondary electron image from transverse view of base material exhibiting tempered martensitic microstructure. Images (a) and (b) are not from the same exact location but are both taken from representative areas of the base material.

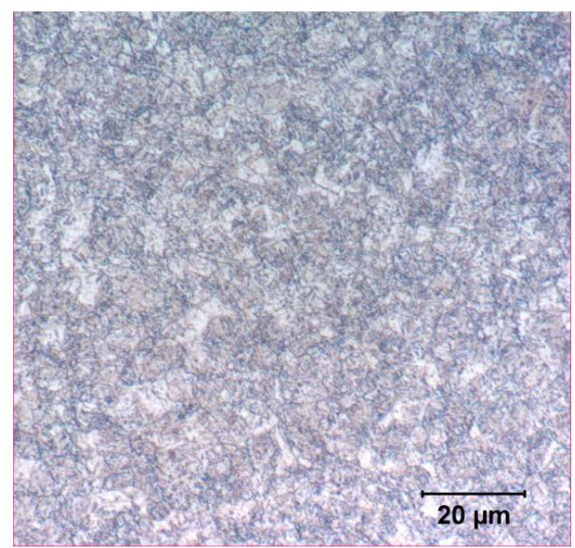

(a)

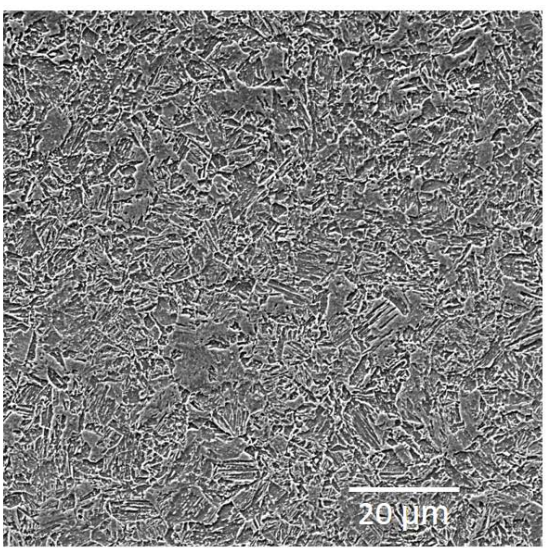

(b)

Figure 5. (a) Optical micrograph and (b) scanning electron microscope secondary electron image from transverse view of $30 \mathrm{amp}$ heat affected zone exhibiting coarse martensitic microstructure. Images (a) and (b) are not from the same exact location but are both taken from representative areas of the heat affected zone. 
base material and the fraction of martensite is noticeably increased as evidenced by smaller grain size (Figure 5 compared to Figure 4). Hardness testing within the HAZ of the $30 \mathrm{~A}$ specimen resulted in a $43 \%$ increase in hardness when compared to the base material.

\subsubsection{Moderate Heat Input (27 amp, $612 \mathrm{~W}$ )}

The microstructure in the HAZ for the 27 amp condition is also coarse tempered martensite. These results are not shown for brevity, but the microstructure of the 27 amp condition was very similar to the $30 \mathrm{amp}$ condition. The grains are smaller than those in the base material and the fraction of martensite is noticeably increased. Hardness testing within the HAZ of the $27 \mathrm{amp}$ specimen resulted in a $42 \%$ increase in hardness when compared to the base material which was virtually identical to the hardness results of the $30 \mathrm{amp}$ condition. There is no major notable difference in either the microstructure or hardness of the $27 \mathrm{amp}$ condition over the $30 \mathrm{amp}$ condition suggesting that there is a threshold condition above which little change in of the workpiece occurs.

\subsubsection{Low Heat Input ( 25 amp, 483 W)}

Unlike in the previous specimen conditions, the microstructure in the HAZ for the $25 \mathrm{~A}$ amp condition did not appear to deviate from the base material as shown in Figure 6. The grains are similar to those of normal tempered martensite as found in Figure 4. Hardness testing within the near-surface heated region of the $25 \mathrm{amp}$ sample shows no significant increase in hardness due to laser heating.

\section{Discussion}

The formation of martensite occurs when a ferrous material is raised beyond the austenite transition (A1) temperature and then is rapidly cooled or quenched. For HY-80 this transition temperature is approximately $727^{\circ} \mathrm{C}$. The transformation of ferrite to austenite and to martensite upon cooling is well established [29]

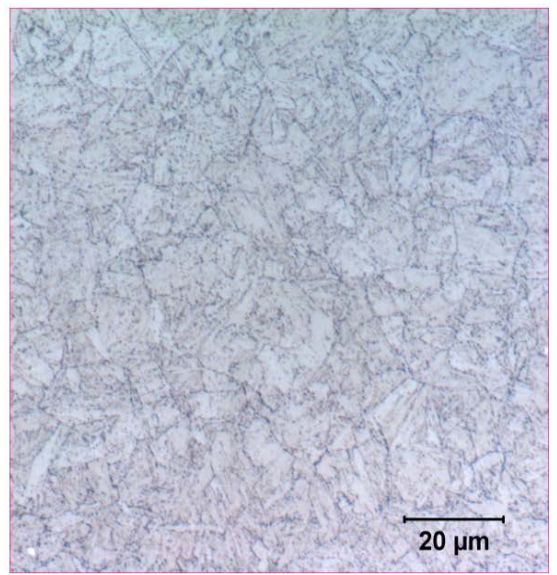

(a)

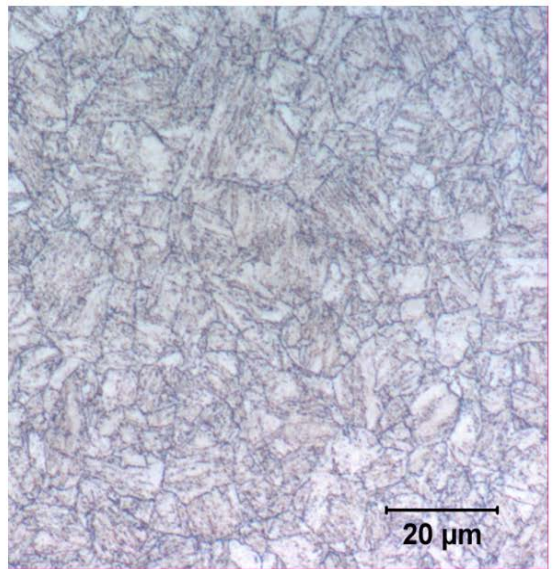

(b)

Figure 6. Optical micrograph of (a) 25 amp heat affected zone and (b) base metal showing no significant change in microstructure at low power. 
and more recently the specifics of these transformations in low-carbon steels following laser heating or joining has also been established [30] [31]. Based on the results from the $25 \mathrm{amp}$ specimens, temperature within the workpiece during the $25 \mathrm{amp}$ condition did not rise above the $\mathrm{A} 1$ temperature.

In previously reported results [17], modelling results of the $25 \mathrm{amp}$ condition showed that temperature remained below the $\mathrm{A} 1$ transition temperature which is consistent with the metallographic results shown here (Figure 6). In this report, the temperature analysis has been extended to the $30 \mathrm{amp}$ condition and the modeling results predicted a temperature profile that includes a HAZ above the A1 transition temperature (Figure 7). The modeling results shown in Figure 7 show the longitudinal temperature profile along the laser path and show the higher temperature behind the laser and lower temperature ahead of the laser (hence the asymmetric shape of the profile in Figure 7). The depth of the temperature profile can be compared to the visible HAZ (shown in later Figures).

Results from this research suggest that a current at or above $27 \mathrm{amp}$ and a scan rate of 100 MMPM does cause HY-80 to rise above the A1 temperature, resulting in visible hardened HAZ regions discussed earlier. When scan rate was held constant at 100 MMPM and HPDL current was varied from $25 \mathrm{amp}$ to 30 amp on a bead-blasted plate, a clear difference in HAZ size as a function of current became evident. Figure 8 compares three transverse sections heated with three different amperages at the same transverse speed. As discussed previously, the $25 \mathrm{amp}$ sample showed no signs of a HAZ, while the $27 \mathrm{amp}$ and $30 \mathrm{amp}$ experienced significant HAZ development. The HAZ for the $30 \mathrm{amp}$ sample was over three times deeper than that the $27 \mathrm{amp}$ condition and over 1.5 times wider. This suggests that small changes in amperage results in dramatic changes in temperature of the work piece and corresponding phase changes. HAZ dimensions

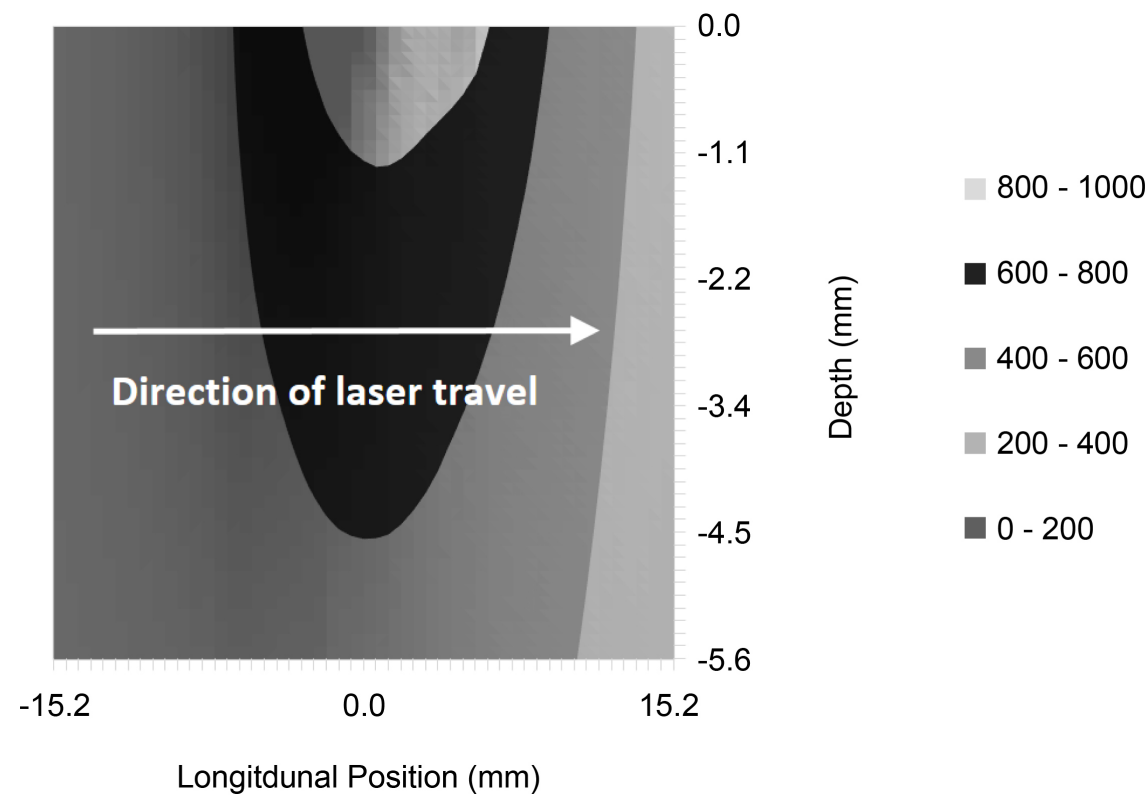

Figure 7. Longitudinal cross-section view of the theoretical temperature field during a steady state portion of a 30 A run at 100 MMPM. 

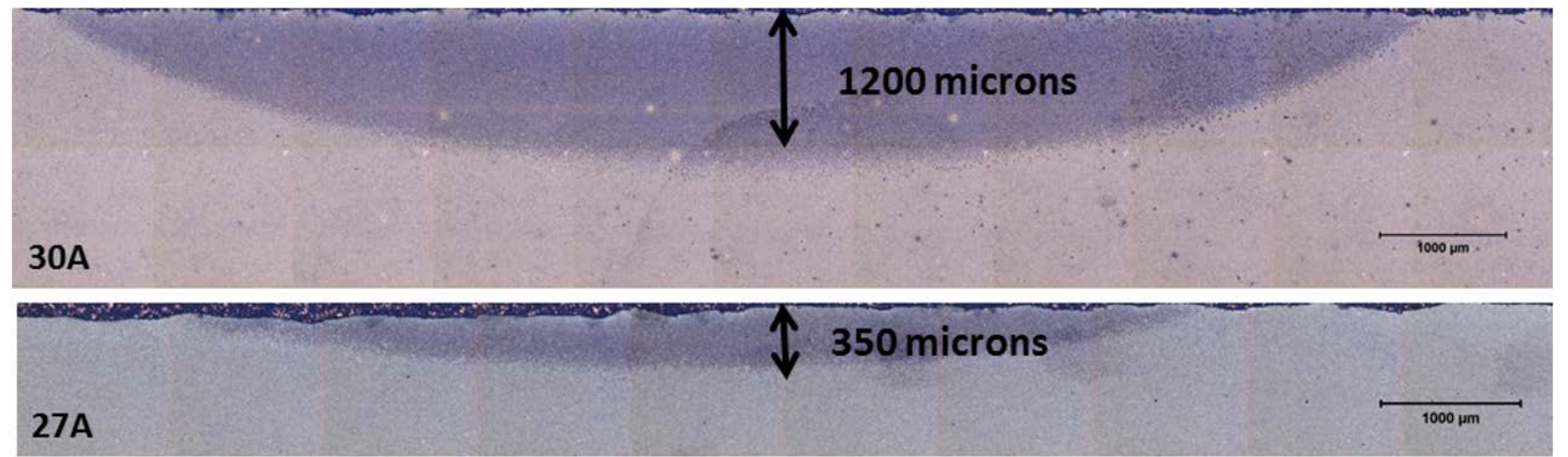

\section{No visible HAZ}

Figure 8. Comparison of 25, 27, and 30 A heat affected zone dimensions at 100 MMPM scan rate.

for each condition are summarized in Table 3. The depth of the HAZ in the 30 amp condition is also notably similar (approximately $1200 \mu \mathrm{m}$ or $1.2 \mathrm{~mm}$ ) to that predicted in Figure 7.

Within a single condition, very distinct transitions between the HAZ and base material were observable using microscopy and hardness analysis. Figure 9 shows three micrographs corresponding to the regions labeled in the macrograph for the $30 \mathrm{amp}$ condition at $100 \mathrm{MMPM}$. Increased martensite is easily identifiable when comparing the base metal and the HAZ by the increased needle-like structure and martensitic grain density. Additionally, the transition zone image provides a clear distinction between the base tempered martensite and the HAZ coarse tempered martensite.

Although the primary goal of DLAFSW is a reduction in tool wear due to workpiece softening, another possible alternative is increased welding speed for a given frictional loading. Because of this, additional traverse speeds were analyzed for the high heat input condition of 30 amps. As expected, increasing the traverse rated reduced the size of the HAZ considerably, as shown in Figure 10. Since the laser array spent less time transferring energy to the workpiece, the HAZ was seven times smaller when the speed was doubled. Although the HAZ was not eliminated, the depth was reduced enough to not affect a significant portion of the material. Future research should focus on whether appropriate softening can take place in conjunction of these increased rates since the minimized HAZ is desirable along with increased welding speeds.

Finally, change in hardness was determined to be directly related to the formation of martensite in the material. Figure 11 is a consolidated plot of hardness versus position for all three laser amperage conditions and clearly shows that the additional formation of martensite due to laser heating above 25 amps causes a marked increase in hardness. The results also show that the relative increase in hardness is the same for both the high heat condition (30 amp) and the moderate heat condition (27 amp) suggesting that increase in hardness is only 
Table 3. Summary of heated affected zone (HAZ) dimensions.

\begin{tabular}{cccc}
\hline $\begin{array}{c}\text { Current } \\
\text { (Amps) }\end{array}$ & Traverse Speed (MMPM) & HAZ Depth (mm) & HAZ Width (mm) \\
\hline 30 & 200 & 0.17 & 6.73 \\
30 & 150 & 0.60 & 9.30 \\
30 & 100 & 1.20 & 10.9 \\
27 & 100 & 0.35 & 6.60 \\
25 & 100 & None & None \\
\hline
\end{tabular}
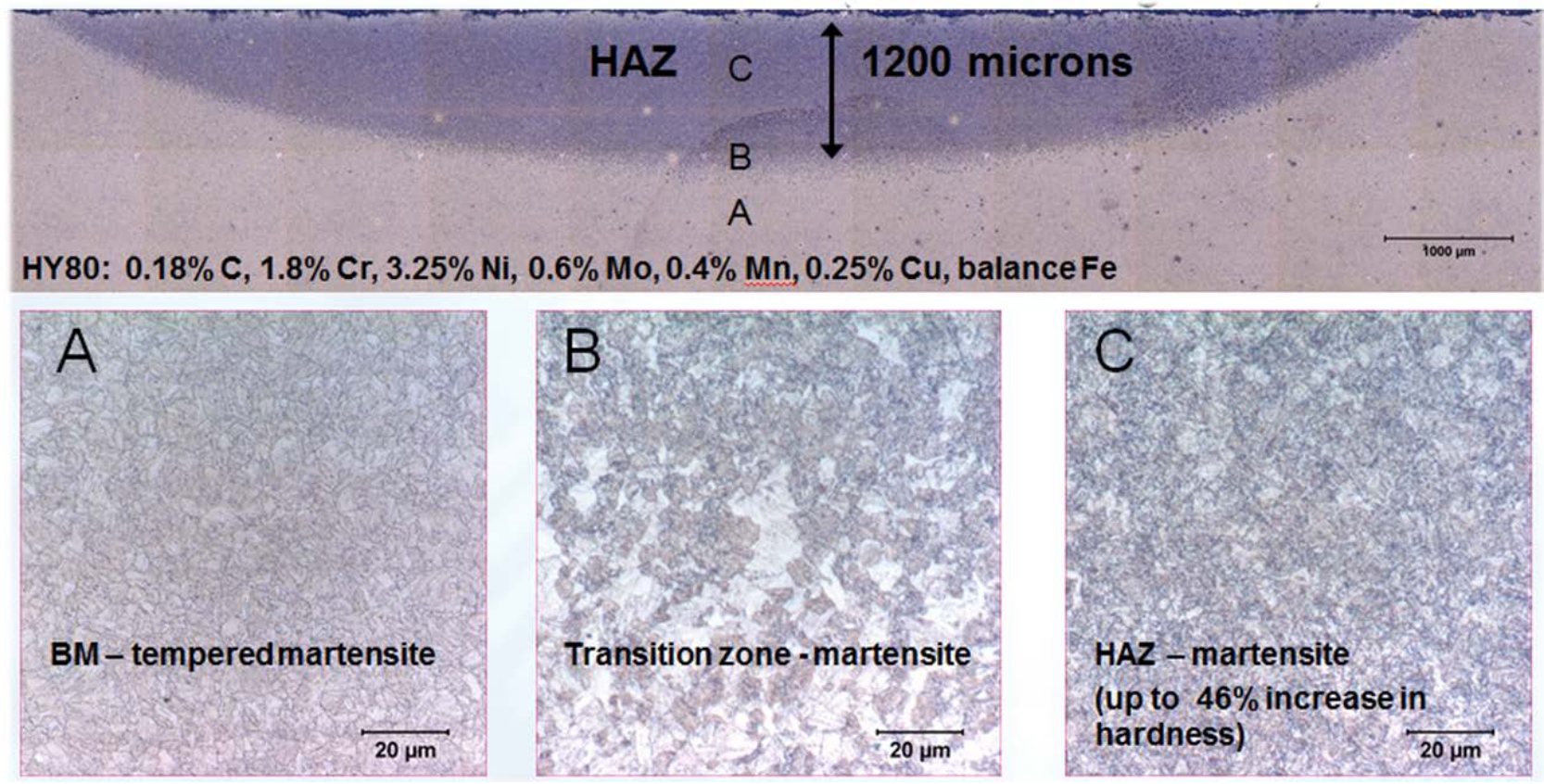

Figure 9. Visible transitions within 30 A 100 MMPM transverse HY-80 specimen.

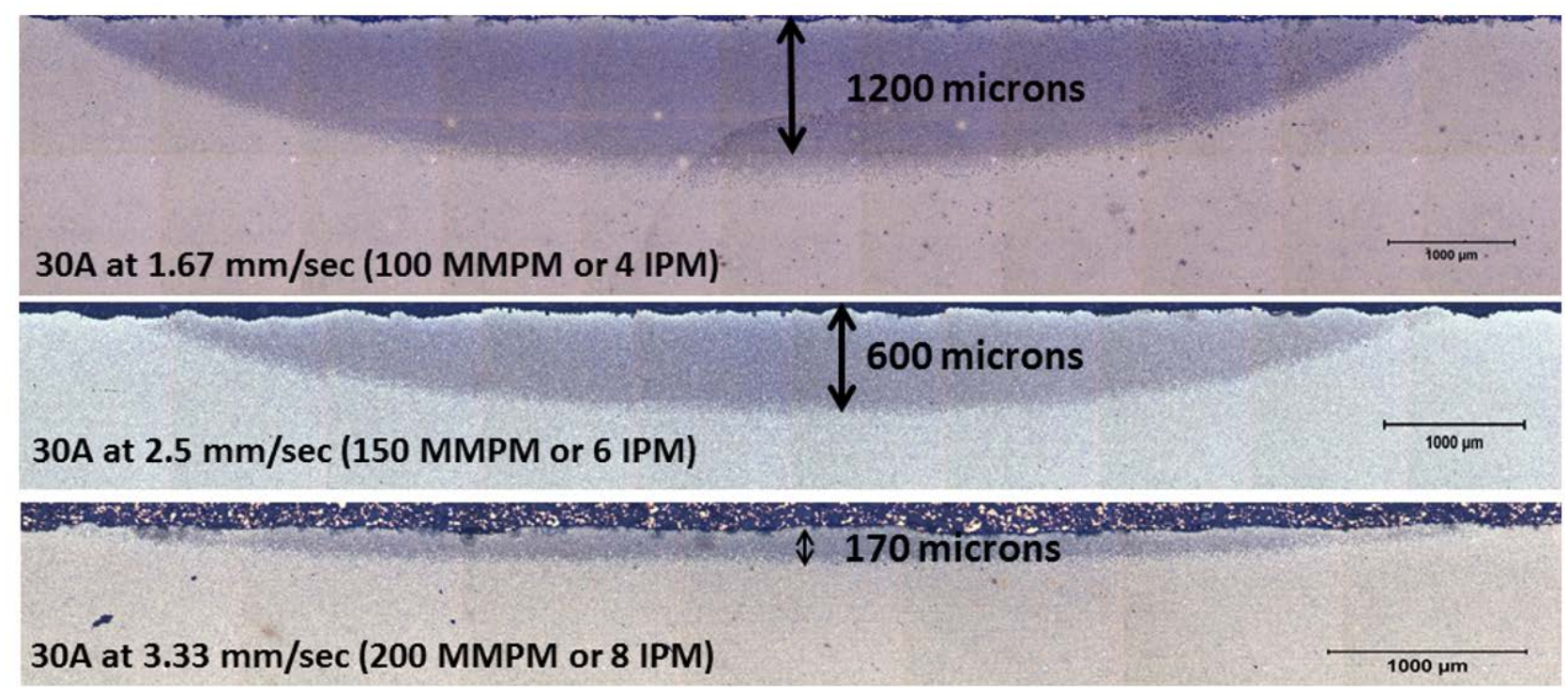

Figure 10. Effect on increasing traverse speed of 30 amp high-power diode laser on HY-80. 
due to the formation of martensite above the A1 temperature not any other grain coarsening effect. Figure 11 also shows that the nominal HAZ for the 27 amp condition is smaller in width than the $30 \mathrm{amp}$ condition in the same manner that Figure 11 shows that the depth of the HAZ is smaller for the same comparison. A summary of hardness results from this research can be found in Table 4.

\section{Conclusions}

Using HPDLs in conjunction with FSW can provide a unique and powerful application for high energy lasers. The improved efficiency, compact size, safety and simplicity of operation of HPDLs make them good candidates for use during machining and surface treatment of steels and in conjunction with a traditional FSW system to make a DLAFSW system. Several conditions of HPDL

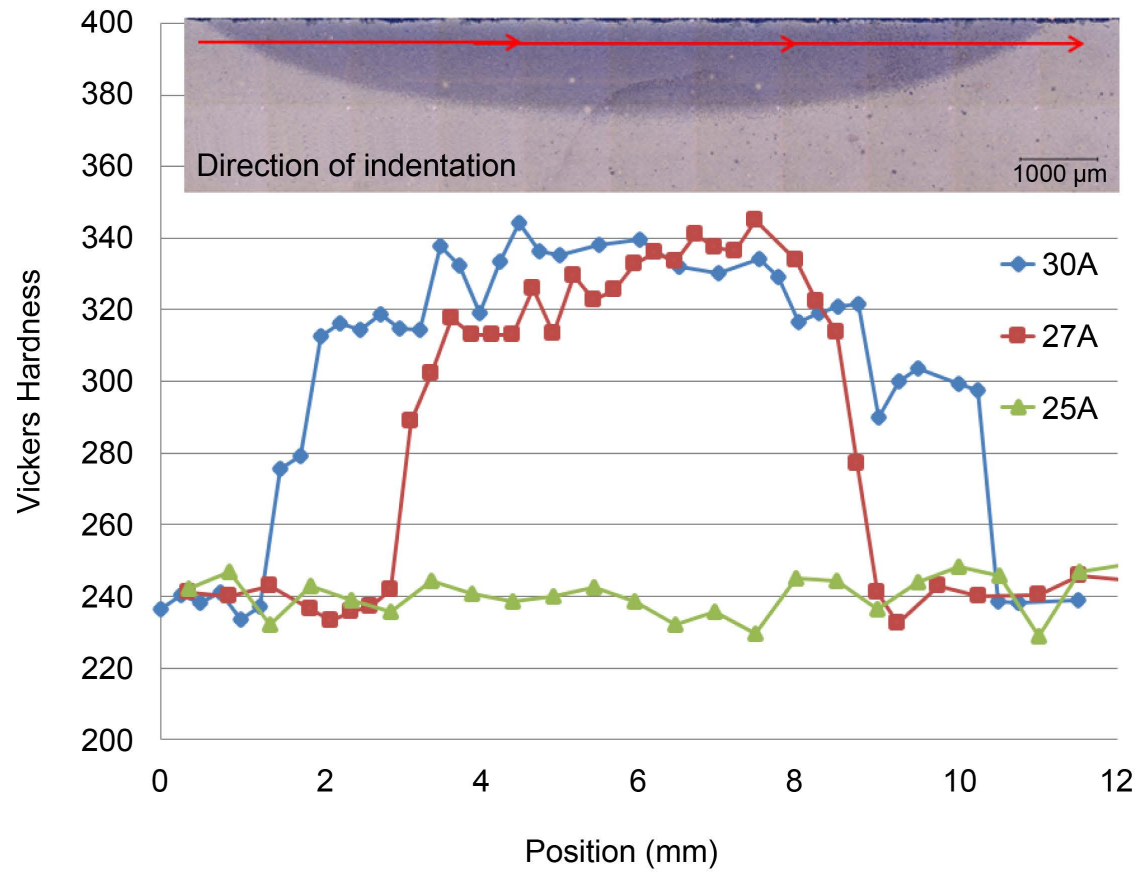

Figure 11. Hardness profiles across heat affected zones for all amperage conditions at normal traverse speeds (100 MMPM). A representative macrograph of the 30 amp condition is shown for reference. Lower amperages produce smaller (in both width and depth) heat affected zones compared to the $30 \mathrm{amp}$ condition.

Table 4. Summary of hardness results.

\begin{tabular}{cccc}
\hline \multirow{2}{*}{$\begin{array}{c}\text { Current } \\
\text { (Amps) }\end{array}$} & $\begin{array}{c}\text { Traverse Speed } \\
(\text { MMPM) }\end{array}$ & \multicolumn{2}{c}{ Percent Increase in Hardness } \\
\cline { 3 - 4 } 30 & 200 & HAZ & Transition Zone \\
30 & 150 & $40 \%$ & $20 \%$ \\
30 & 100 & $42 \%$ & $23 \%$ \\
27 & 100 & $46 \%$ & $21 \%$ \\
25 & 100 & $42 \%$ & $24 \%$ \\
\hline
\end{tabular}


parameters for use in DLAFSW were analyzed in this research for optimization on HY-80 steel. The following conclusions were made:

- Laser operation at less than 27 amps results in no noticeable change in microstructure at a steady traverse speed of 100 MMPM. Conversely, laser operation at 27 amps or greater causes a noticeable HAZ and change in microstructure.

- The HAZ of laser heated HY-80 rises above the A1 temperature and experiences approximately $40 \%$ increase in hardness when compared to the base metal after cooling. This increase in hardness is directly due to increased martensite formation.

- An increase in traverse rate significantly reduces the size of the HAZ which may allow for faster manufacturing.

- The formation of a HAZ and additional brittle martensite in HY-80 can be prevented through the optimization of laser amperage and transverse speed.

\section{Acknowledgements}

The authors are eternally grateful to have received guidance from and worked with the late Dr. W. Howard Lowdermilk, to whom this article is dedicated. This work was funded through a Laboratory Directed Research and Development grant 15-ERD-037 and performed under the auspices of the U.S. Department of Energy by Lawrence Livermore National Laboratory under contract DE-AC5207NA27344.

\section{References}

[1] Thomas, W.M., Nicholas, E.D., Needham, J.C., Murch, M.G., Templesmith, P. and Dawes, C.J. (1991) G.B. Patent Application No. 9125978.8.

[2] Thomas, W.M., Threadgill, P.L. and Nicholas, E.D. (1999) Feasibility of Friction Stir Welding Steel. Science and Technology of Welding and Joining, 4, 365-372. https://doi.org/10.1179/136217199101538012

[3] Mishra, R.S. and Ma, Z.Y. (2005) Friction Stir Welding and Processing. Materials Science and Engineering, 50, 1-78. https://doi.org/10.1016/j.mser.2005.07.001

[4] Nandan, R., DebRoy, T. and Bhadeshia, H.K.D.H. (2008) Recent Advances in Friction-Stir Welding-Process, Weldment Structure and Properties. Progress in Materials Science, 53, 980-1023. https://doi.org/10.1016/j.pmatsci.2008.05.001

[5] Steuwer, A., Barnes, S.J., Altenkirch, J., Johnson, R. and Withers, P.J. (2012) Friction Stir Welding of HSLA-65 Steel: Part II. The Influence of Weld Speed and Tool Material on the Residual Stress Distribution and Tool Wear. Metallurgical and Materials Transactions A, 43, 2356-2365. https://doi.org/10.1007/s11661-011-0643-X

[6] Prado, R.A., Murr, L.E., Shindo, D.J. and Soto, K.F. (2001) Tool Wear in the Friction-Stir Welding of Aluminum Alloy $6061+20 \% \mathrm{Al}_{2} \mathrm{O}_{3}$ : A Preliminary Study. Scripta Materialia, 45, 75-80. https://doi.org/10.1016/S1359-6462(01)00994-0

[7] Ferrando, W.A. (2008) The Concept of Electrically Assisted Friction Stir Welding (EAFSW) and Application to the Processing of Various Metals. Naval Surface Warfare Center, Carderock Div, Bethesda, MD, Survivability Structures and Materials Directorate, No. NSWCCD-61-TR-2008/13.

[8] Montazerolghaem, H., Badrossamay, M. and Tehrani, A.F. (2012) Investigation of 
Vibration Assisted Friction Stir Welding. Key Engineering Materials, 504-506, 741 746. https://doi.org/10.4028/www.scientific.net/kem.504-506.741

[9] Sinclair, P.C., Longhurst, W.R., Cox, C.D., Lammlein, D.H., Strauss, A.M. and Cook, G.E. (2010) Heated Friction Stir Welding: An Experimental and Theoretical Investigation into How Preheating Influences Process Forces. Materials and Manufacturing Processes, 25, 1283-1291. https://doi.org/10.1080/10426914.2010.496122

[10] Bang, H., Bang, H., Jeon, G., Oh, I. and Ro, C. (2012) Gas Tungsten Arc Welding Assisted Hybrid Friction Stir Welding of Dissimilar Materials Al6061-T6 Aluminum Alloy and STS304 Stainless Steel. Materials \& Design, 37, 48-55. https://doi.org/10.1016/j.matdes.2011.12.018

[11] HanSur, B., HeeSeon, B., HyunJong, S. and SungMin, J. (2013) Joint Properties of Dissimilar Al6061-T6 Aluminum Alloy/Ti-6\%Al-4\%V Titanium Alloy by Gas Tungsten Arc Welding Assisted Hybrid Friction Stir Welding. Materials \& Design, 51, 544-551. https://doi.org/10.1016/j.matdes.2013.04.057

[12] Scutelnicu, E., Birsan, D. and Cojocaru, R. (2011) Recent Advances in Manufacturing Engineering. Proceedings of the 4th International Conference on Manufacturing Engineering, Quality and Production Systems, Barcelona, 15-17 September 2011, 97-102.

[13] Tweedy, B.M., Arbegast, W. and Allen, C. (2005) Friction Stir Welding Processing III. Wiley, Hoboken, 97-104.

[14] Kohn, G., Greenberg, Y., Makover, I. and Munitz, A. (2002) Laser-Assisted Friction Stir Welding. Welding Journal, 81, 46-48.

[15] Casalino, G., Campanelli, S., Ludovico, A.D., Contuzzi, N. and Angelastro, A. (2012) High Power Laser Materials Processing: Lasers, Beam Delivery, Diagnostics, and Applications.

[16] Merklein, M. and Giera, A. (2008) Laser Assisted Friction Stir Welding of Drawable Steel-Aluminium Tailored Hybrids. International Journal of Material Forming, 1, 1299-1302. https://doi.org/10.1007/s12289-008-0141-X

[17] Baker, B.W., McNelley, T.R., Matthews, M.J., Rotter, M., Rubenchik, A. and Wu, S. (2015) Use of High-Power Diode Laser Array for Pre- and Post-Weld Heating During Friciton Stir Welding of Steels. In: Mishra, R.S., Ed., Friction Stir Welding and Processing VIII, Springer, Berlin, 21-26.

https://doi.org/10.1007/978-3-319-48173-9_3

[18] Reynolds, A.P., Tang, W., Posada, M. and DeLoach, J. (2003) Friction Stir Welding of DH36 Steel. Science and Technology of Welding and Joining, 8, 455-460. https://doi.org/10.1179/136217103225009125

[19] Baker, B., Menon, E.S., McNelley, T., Brewer, L., El-Dasher, B., Farmer, J., Torres, S. and Mahoney, M. (2014) Processing-Microstructure Relationships in Friction Stir Welding of MA956 Oxide Dispersion Strengthened Steel. Metallurgical and Materials Transactions E, 1-13.

[20] Li, L. (2000) The Advances and Characteristics of High-Power Diode Laser Materials Processing. Optics and Lasers in Engineering, 34, 231-253. https://doi.org/10.1016/S0143-8166(00)00066-X

[21] Chen, W.Q., Roychoudhuri, C.S. and Banas, C.M. (1994) Design Approaches for Laser-Diode Material-Processing Systems Using Fibers and Micro-Optics. Optical Engineering, 33, 3662-3669. https://doi.org/10.1117/12.183489

[22] Bachmann, F. (2003) Industrial Applications of High Power Diode Lasers in Materials Processing. Applied Surface Science, 208, 125-136.

https://doi.org/10.1016/S0169-4332(02)01349-1 
[23] Heller, S.R., Fioriti, I. and Vasta, J. (1965) An Evaluation of Hy-80 Steel as a Structural Material for Submarines. Naval Engineers Journal, 77, 29-44. https://doi.org/10.1111/j.1559-3584.1965.tb05644.x

[24] Stewart, W.C. (2011) Mechanical and Aerospace Engineering. Naval Postgraduate School, Monterey.

[25] Young, G.W. (2012) Mechanical and Aerospace Engineering Department. Naval Postgraduate School, Monterey.

[26] Shi, B. and Attia, H. (2013) Integrated Process of Laser-Assisted Machining and Laser Surface Heat Treatment. Journal of Manufacturing Science and Engineering, 135, Article ID: 061021. https://doi.org/10.1115/1.4025832

[27] Halverson, B. and Hinrichs, J.F. (2007) Friction Stir Welding (FSW) of Littoral Combat Ship Deckhouse Structure. Journal of Ship Production, 23, 3.

[28] Cheng, C., Lin, H. and Lin, J. (2010) Friction Stir Welding of Ductile Iron and Low Carbon Steel. Science and Technology of Welding and Joining, 15, 706-711. https://doi.org/10.1179/136217110X12785889549507

[29] Koistinen, D. and Marburger, R. (1959) A General Equation Prescribing the Extent of the Austenite-Martensite Transformation in Pure Iron-Carbon Alloys and Plain Carbon Steels. Acta Metallurgica, 7, 59-60. https://doi.org/10.1016/0001-6160(59)90170-1

[30] Lo, K.H., Cheng, F.T. and Man, H.C. (2003) Laser Transformation Hardening of AISI 440C Martensitic Stainless Steel for Higher Cavitation Erosion Resistance. Surface and Coatings Technology, 173, 96-104. https://doi.org/10.1016/S0257-8972(03)00347-5

[31] Xia, M., Biro, E., Tian, Z. and Zhou, Y.N. (2008) Effects of Heat Input and Martensite on HAZ Softening in Laser Welding of Dual Phase Steels. ISIJ International, 48, 809-814. https://doi.org/10.2355/isijinternational.48.809

\section{Submit or recommend next manuscript to SCIRP and we will provide best service for you:}

Accepting pre-submission inquiries through Email, Facebook, LinkedIn, Twitter, etc. A wide selection of journals (inclusive of 9 subjects, more than 200 journals)

Providing 24-hour high-quality service

User-friendly online submission system

Fair and swift peer-review system

Efficient typesetting and proofreading procedure

Display of the result of downloads and visits, as well as the number of cited articles

Maximum dissemination of your research work

Submit your manuscript at: http://papersubmission.scirp.org/

Or contact wjet@scirp.org 